Original research

\title{
Clinicians' involvement in data collection for portfolio research: impact on their clinical practice and perception of research
}

David Sweeting, Physiotherapy Clinical Specialist, East Coast Community Healthcare CIC, Great Yarmouth and Waveney, UK

Helena Daniell, Practice Development and Research Lead Physiotherapist, Norfolk and Norwich University Hospital, Norwich, UK

Rachel Chester, Lecturer in Physiotherapy, School of Health Sciences, Faculty of Medicine and Health, University of East Anglia, Norwich, Norfolk NR4 7TJ UK

Correspondence to: David Sweeting (David.sweeting@nhs.net)

Received: 30 October 2018; Accepted: 5 August 2019

\begin{abstract}
Background/Aims Physiotherapists generally have a positive view to research, but have identified a number of barriers to taking part, and have expressed challenges when attempting to integrate research findings into their practice The aim of this study was to describe the self-reported impact of collecting data for a multicentre research study on physiotherapists' clinical practice.
\end{abstract}

Methods Convenience sampling was used to select three of 11 NHS trusts involved in the original data collection. A questionnaire was emailed to the 28 of 34 physiotherapists working within these three Trusts who collected data and for whom contact details were available.

Results A total of 21 (75\%) physiotherapists completed the questionnaire. Out of the 21 physiotherapists, 15 of these stated they were aware of the study results; all of whom reported subsequent changes in their beliefs about prognostic factors for shoulder pain (subject of the original study) and some alteration in clinical practice. However, barriers to integrating further changes into practice were reported, including lack of time and a perception that patients would not engage with a more (bio) psychosocial approach. Overall, $85 \%$ of responders stated data collection had changed their understanding of the research process.

Conclusions Clinicians' participation in the research process positively influenced practice. However, 29\% [AQ: please change to \%] were unaware of the results and only $33 \%$ of physiotherapists accessed the published article. There were perceived barriers to integrating results into practice.

Key words Clinician involvement, Data collection, Impact, Research

\section{Introduction}

Health research should lead to improvements in healthcare (Health Research Authority (HRA), 2017a). Frontline clinicians are encouraged to become involved in research on the basis that it will benefit themselves, their organisation and their patients (HRA 2017a, National Institute for Health Research (NIHR), 2018a). 
Physiotherapists who work in a clinical setting generally have a positive view to research, but have identified a number of barriers to taking part, and have expressed challenges when attempting to apply and integrate research findings into their practice (Janssen et al, 2016). For instance, Janssen et al (2016) established that lack of time was perceived as a barrier to undertaking research, and both Metcalfe et al (2001) and Janssen et al (2016), reported that some health professionals - including physiotherapists - struggle to access databases, feel overwhelmed by the volume of available literature and can find the literature difficult to understand and relate to their own practice. It is unknown whether these same perceptions of research and barriers are also shared by physiotherapists who work clinically and are also actively involved in research.

Aim

The purpose of this study was to explore the self-perceived impact of collecting data for an NIHR portfolio study on physiotherapists' clinical practice, and their perceptions of research. We also sought to explore the awareness physiotherapists had of the study results and the impact of the study's results on their clinical practice.

\section{Methods}

This survey used a bespoke questionnaire (Appendix 1). The research selected for our project was an NIHR portfolio study investigating prognostic factors associated with the outcome of physiotherapy management for musculoskeletal shoulder pain (Chester et al, 2013, 2016). This selection was based on the author's (RC) objective of the original study to assess the impact of data collection and dissemination of results on the clinical practice and research understanding from the perspective of clinicians participating in the research. Data collection was undertaken by 155 physiotherapists based in 11 NHS Trusts and social enterprises throughout the East of England between 2011 and 2013. Results were published online in 2016, and all participating physiotherapists for whom contact details were available were sent an electronic link via email to the free access publication.

Three sites were selected based on convenience sampling. A bespoke questionnaire was developed by the authors for participating clinicians to complete (Appendix 1). The questionnaire covered three key areas: perceived impact of study results on current clinical practice, perceived impact on future clinical practice and perception of research as a result of their involvement in the data collection process. Closed questions were followed by open questions, which allowed respondents to explain their answers.

All participating physiotherapists were sent the questionnaire by email. Participants were encouraged to complete the questionnaire even if they had little or no knowledge of the study findings, and were advised that they could complete and return the questionnaire electronically or anonymously via a hard copy.

Data for each of the three individual sites were collected by the author based at that site and then collated by the lead author (DS). All participants were given an identifier number to provide anonymity. For each item or question, descriptive statistics were used to present the frequency of responses for each category. This was undertaken using Microsoft Excel 2010. Some respondents did not answer every question. Comments were collated independently by the authors into common themes based around the items/questions to which they referred.

Ethical approval 
The NHS Health Research Authority algorithm (Health Research Authority, 2017b) stated that formal ethical approval was not required.

\section{Results}

A total of 34 physiotherapists were identified at the three Trusts, of which 28 were contactable and were sent the questionnaire. Out of the 28 who were emailed, $21(75 \%)$ returned completed questionnaires (13 of 18 from community services and 8 of 16 from secondary care) (Figure 1). Of these, 15 (71\%) (10 from community services and 5 from secondary care) stated that they were aware of the results from the portfolio study. [AQ: from the portfolio study?]. Awareness came from a variety of sources, with only five (33\%) participants stating that they had read the publication of results. Other sources included direct contact with the author $(n=4 ; 19 \%)$, social media $(n=1 ; 5 \%)$, postgraduate courses $(n=4 ; 19 \%)$ and conversations with colleagues $(n=2 ; 9.5 \%)$. Note: one physiotherapist cited more than one source of awareness.

Figure 1. Recruitment.

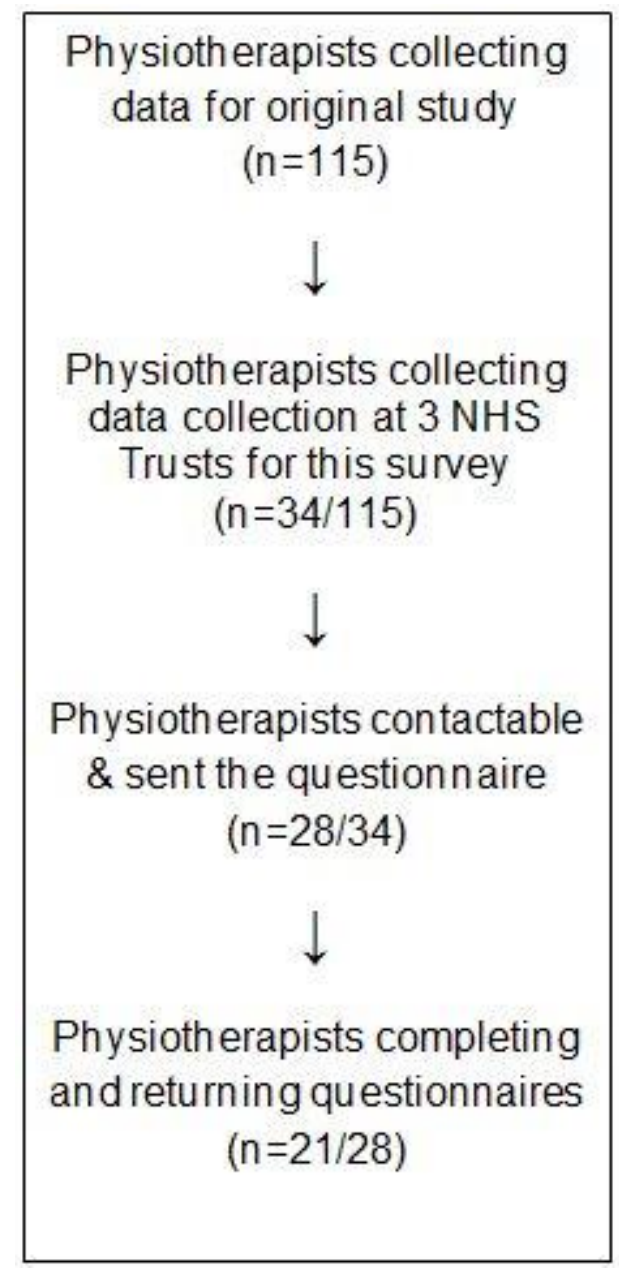

All participants who were aware of the results stated that they understood them, and that this understanding had changed their beliefs about factors contributing to the prognosis of individuals receiving physiotherapy for shoulder pain. Of these, all provided some detail of these changes, the most commonly cited being the importance of psychosocial factors; particularly patients' expectations for recovery $(n=10 ; 48 \%)$.

Impact of results on clinical practice 
Respondents were asked whether their participation in the project or their knowledge of the results had changed their clinical practice in any way. A total of $20(95 \%)$ respondents answered these questions. All reported making changes to their current practice. Of these, 15 (75\%), reported making changes to their subjective assessment process, and $12(60 \%)$ reported changes in their physical assessment process; with the most common change $(n=8 ; 40 \%)$ being reduced emphasis on this physical component of the assessment:

'I am trying to change my method of questioning, trying not to lead the patient to say what they think I want them to say so that I can find out their true beliefs and understanding of their condition.'

'As time to assess is limited I spend less time on the "special tests", and therefore probably devote more time to discussion with the patient.'

A total of $16(80 \%)$ participants reported making changes to their patient management, particularly in terms of patient expectations of recovery and locus of control:

'I ensure I emphasise their ability to improve their own symptoms. I did this before but do it with more confidence now that I can support the message with research.'

The number of participants making changes to specific areas of their practice is shown in Table 1. Despite the impact on their personal professional practice, none of the responders felt that the results of the study had been directly incorporated within or changed any local or regional guidelines, pathways or documentation.

Table 1. Changes in practice.

\begin{tabular}{|c|c|}
\hline $\begin{array}{l}\text { Component of practice } \\
(n=\text { number of participants) }\end{array}$ & $\begin{array}{l}\text { Nature of change } \\
\text { ( } n=\text { number of participants) }\end{array}$ \\
\hline \multirow[t]{3}{*}{ Subjective assessment } & $\begin{array}{l}\text { Increased emphasis on psychosocial factors } \\
\text { including patient expectation of recovery (12) }\end{array}$ \\
\hline & Less directive questioning style (1) \\
\hline & $\begin{array}{l}\text { Respondents who did not define nature of } \\
\text { change (2) }\end{array}$ \\
\hline \multirow{3}{*}{$\begin{array}{l}\text { Physical assessment } \\
\text { (12) } \\
\text { Note: some responders } \\
\text { described }>1 \text { change }\end{array}$} & $\begin{array}{l}\text { Reduced focus on physical assessment / } \\
\text { special tests versus subjective findings (8) }\end{array}$ \\
\hline & $\begin{array}{l}\text { [Increased or new] use of measurement } \\
\text { equipment; goniometer, myometer (5) }\end{array}$ \\
\hline & $\begin{array}{l}\text { [Increased or new] use of symptom } \\
\text { modification procedure (2) }\end{array}$ \\
\hline
\end{tabular}




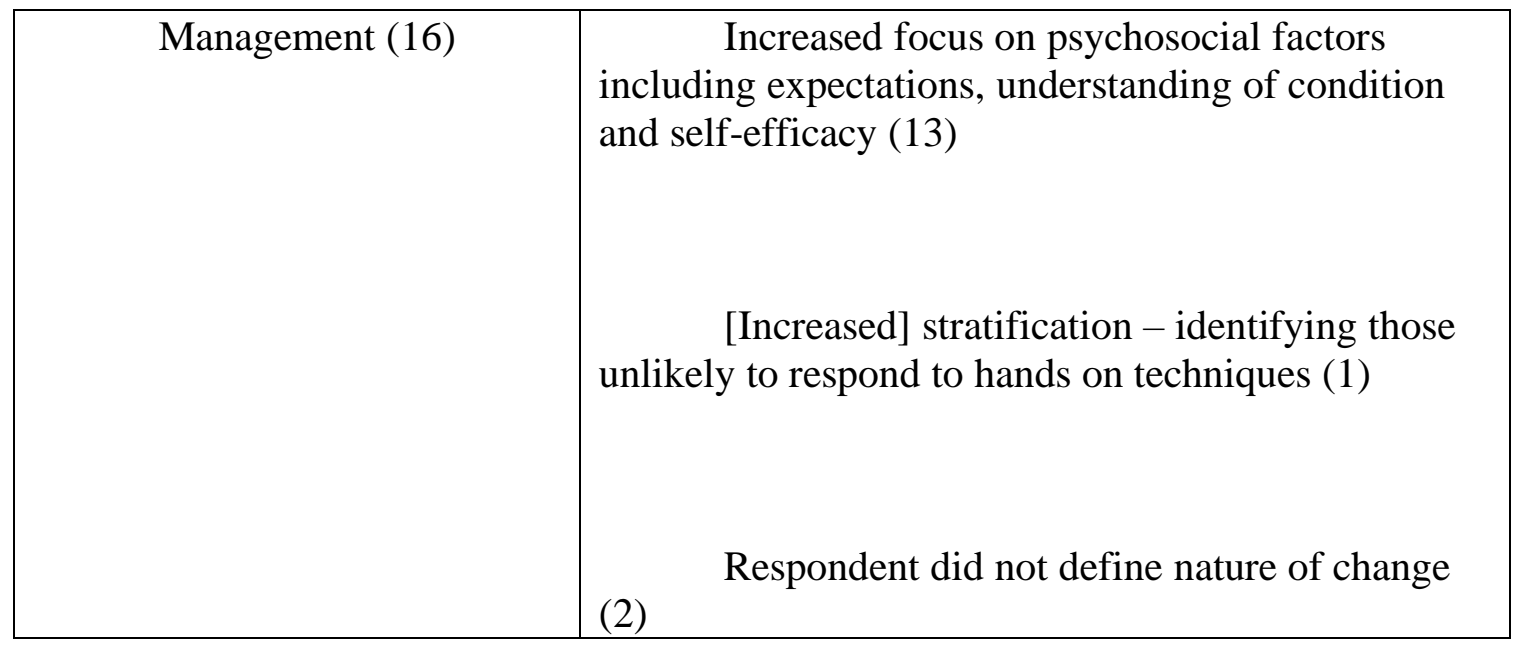

The facilitators and barriers to incorporating the results of the study into practice are outlined in Table 2. The most frequently mentioned barriers were perceived difficulty gaining patient engagement and perceived patient expectation of a biomedical approach $(n=7 ; 35 \%)$ and lack of time $(n=6 ; 30 \%)$. Facilitators included improved confidence, specifically from the way that the findings of this study aligned with other evidence and the support of their peers.

Table 2. Barriers and facilitators.

\begin{tabular}{|c|c|}
\hline $\begin{array}{l}\text { Barrier and facilitator and number of } \\
\text { participants commenting } \\
\text { ( } n=\text { number of participants })\end{array}$ & $\begin{array}{l}\text { Specific factors } \\
\text { ( } n=\text { number of participants) }\end{array}$ \\
\hline Barriers (19) & $\begin{array}{l}\text { Lack of time (6) } \\
\text { Patient engagement/expectations of } \\
\text { care (7) } \\
\text { Difficulty changing old habits (2) } \\
\text { Ongoing changes within Department } \\
\text { (2) Contradictory messages from } \\
\text { previous clinicians (1) } \\
\text { Information Technology - templates }\end{array}$ \\
\hline
\end{tabular}




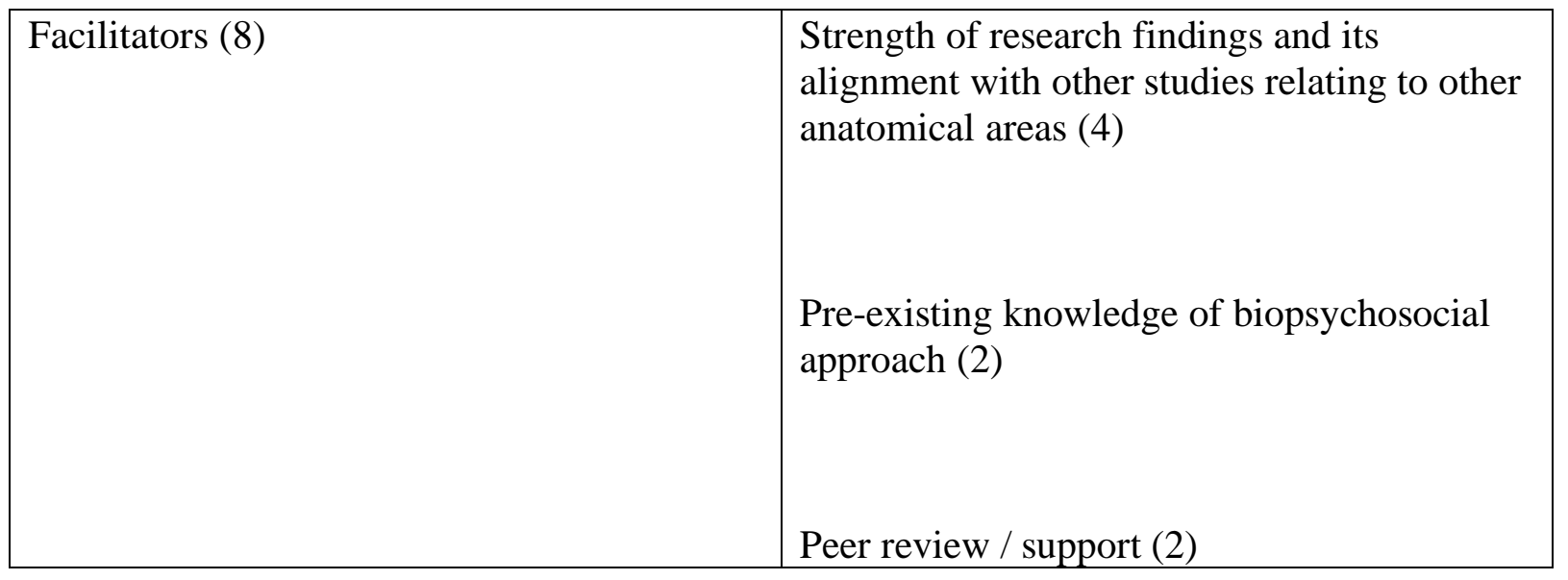

'Some people will not engage despite lots of information/education. This can be frustrating'

'We have only 30 minutes for a new patient and it is quicker just to look and feel.'

A total of 10 respondents $(50 \%)$ stated that they had identified additional training requirements as a result of the study. The majority of these $(n=7 ; 35 \%)$ were related to communication skills and the assessment/management of psychosocial factors. Out of these 10 respondents, 2 participants (10\%) suggested that specific training related to the study results would have been helpful. None of those who identified training needs felt that these had been more than partially met.

Impact of involvement in the data collection process

Respondents were asked to rate the benefits of their involvement in the research process using a scale from 0 (no benefit) to 5 (maximum benefit). See Table 3 for results. All respondents reported that the value of their involvement in the research process outweighed the inconvenience. Out of 20 respondents, 17 (85\%) felt that involvement in data collection had changed their understanding of the research process. Explanations included better understanding of the practicalities of research $(n=4 ; 20 \%)$, and the need for accuracy and rigour when collecting data $(n=3 ; 15 \%)$. However, $70 \%$ of respondents $(n=14)$ [AQ: $n=14$ ?] stated some degree of inconvenience. This view was more prevalent among the respondents based in community services than those working in secondary care. Results are presented in Table 4.

Table 3. Benefits of involvement in the data collection process.

\begin{tabular}{|c|c|c|c|c|c|c|c|}
\hline \multirow[t]{2}{*}{ Category } & \multicolumn{7}{|c|}{ Level of benefit: $0=$ of no benefit and $5=$ of maximum benefit } \\
\hline & 0 & 1 & 2 & 3 & 4 & 5 & Unsure \\
\hline $\begin{array}{l}\text { For your continuing professional } \\
\text { development } \\
n=20\end{array}$ & Nil & Nil & $\begin{array}{l}3 \\
(15 \%)\end{array}$ & $\begin{array}{l}6 \\
(30 \%)\end{array}$ & $\begin{array}{l}4 \\
(20 \%)\end{array}$ & $\begin{array}{l}6 \\
(30 \%)\end{array}$ & $\begin{array}{l}1 \\
(5 \%)\end{array}$ \\
\hline
\end{tabular}




\begin{tabular}{|c|c|c|c|c|c|c|c|}
\hline $\begin{array}{l}\text { As a source of revenue for the } \\
\text { physiotherapy department } \\
n=20\end{array}$ & $\begin{array}{l}1 \\
(5 \%)\end{array}$ & $\begin{array}{l}1 \\
(5 \%)\end{array}$ & $1(5 \%)$ & $\begin{array}{l}3 \\
(15 \%)\end{array}$ & $\begin{array}{l}2 \\
(10 \%)\end{array}$ & $\begin{array}{l}3 \\
(15 \%)\end{array}$ & $\begin{array}{l}9 \\
(45 \%)\end{array}$ \\
\hline $\begin{array}{l}\text { As kudos for your physiotherapy } \\
\text { department } \\
n=20\end{array}$ & Nil & Nil & $\begin{array}{l}1 \\
(5 \%)\end{array}$ & $\begin{array}{l}7 \\
(35 \%)\end{array}$ & $\begin{array}{l}7 \\
(35 \%)\end{array}$ & $\begin{array}{l}4 \\
(20 \%)\end{array}$ & $\begin{array}{l}1 \\
(5 \%)\end{array}$ \\
\hline $\begin{array}{l}\text { For 'patient/person-centred care' } \\
n=20\end{array}$ & Nil & $1(5 \%)$ & $\begin{array}{l}1 \\
(5 \%)\end{array}$ & $\begin{array}{l}8 \\
(40 \%)\end{array}$ & $\begin{array}{l}5 \\
(25 \%)\end{array}$ & $\begin{array}{l}5 \\
(25 \%)\end{array}$ & Nil \\
\hline $\begin{array}{l}\text { For the physiotherapy profession } \\
n=20\end{array}$ & Nil & Nil & $\begin{array}{l}1 \\
(5 \%)\end{array}$ & $\begin{array}{l}2 \\
(10 \%)\end{array}$ & $\begin{array}{l}7 \\
(35 \%)\end{array}$ & $\begin{array}{l}10 \\
(50 \%)\end{array}$ & Nil \\
\hline
\end{tabular}

Table 4. Was your involvement in the research an inconvenience? $(n=20)$.

\begin{tabular}{|c|c|c|c|}
\hline $\begin{array}{l}\text { Yes, it was more of } \\
\text { an inconvenience } \\
\text { than of any benefit }\end{array}$ & $\begin{array}{l}\text { Yes, rather } \\
\text { inconvenient, but } \\
\text { worth it }\end{array}$ & $\begin{array}{l}\text { A little inconvenient } \\
\text { but not noticeably }\end{array}$ & $\begin{array}{l}\text { No inconvenience at } \\
\text { all }\end{array}$ \\
\hline Nil & $\begin{array}{c}5 \\
\text { (community } 4 \text { of } 5 \text {, } \\
\text { secondary care } 1 \text { of } \\
5 \text { ) }\end{array}$ & $\begin{array}{c}9 \\
\text { (community } 7 \text { of } 9, \\
\text { secondary care } 2 \text { of } \\
9 \text { ) }\end{array}$ & $\begin{array}{l}6 \\
6 \\
\text { (community } 2 \text { of } 6 \text {, } \\
\text { secondary care } 4 \text { of } \\
6 \text { ) }\end{array}$ \\
\hline
\end{tabular}

\section{Discussion}

Dissemination and awareness of study findings

The NIHR document providing advice to researchers regarding disseminating findings quotes Professor Chris Whitty, Chief Scientific Adviser for the Department of Health, 'Research is of no use unless it gets to the people who need to use it' (NIHR, 2018b). Of the 21 physiotherapists who completed the survey, 15 stated that they were aware of and understood the results. Physiotherapists taking part in the study had been sent a link to the free access article, published in the British Journal of Sports Medicine (Chester et al, 2016). A third of physiotherapists taking part in the present study stated they had accessed the article. Hannes et al (2009), identified that physiotherapists can have difficulty accessing the information they want and can find the scientific language difficult. Hannes et al (2009) go on to suggest that this may be driven by scientists only publishing in scientific journals because of the associated academic credits. Authors need to look beyond publication in peer reviewed academic journals if they are to disseminate more effectively. 
The need to modernise and improve dissemination of results was discussed at the Physiotherapy Research Society Annual Conference (2018). The sample in the present study is small, but if representative, then it highlights the importance of additional methods of disseminating research findings. In addition to postgraduate courses, our respondents highlighted the importance of social media and peer discussion.

Impact on clinical practice

The findings are supportive that involvement in research activity will lead to perceived improvements in healthcare (Health Research Authority, 2017a). All respondents reported having made some change to clinical practice as a result of their involvement in the data collection process. These were predominantly around increased awareness of psychosocial factors, reduced reliance on 'special tests' and greater use of equipment to improve accuracy of objective measures.

The findings had much in common with those of Boaz et al (2015) who conducted a threestage review and concluded that involvement in research activity does improve performance, primarily in terms of processes such as awareness of study findings, applying the processes involved beyond the trial and seeing increased relevance of the research.

The present study did not seek to assess impact in terms of clinical outcome, but Clarke and Louden (2011) report that research involvement may lead to improved outcomes for patients involved in the study. However, they state that the evidence is inconsistent and should be considered with caution. Neither Boaz et al (2015) nor Clarke and Louden (2011) included physiotherapy studies within their reports and research into this area would be valuable.

Respondents were over twice as likely to report barriers to implementing change $(n=19)$ than facilitators $(n=8)$. Foremost among barriers was lack of time, and perceptions that patients would not engage with a more psychosocial approach. These findings are consistent with those of Bernhardsson et al (2014) and Kamwendo (2002), who identified that lack of time and high work load are among the primary reasons why evidence may not be translated into clinical practice.

Organisations that wish their physiotherapists to make evidence-led changes to practice will need to look at ways of supporting them in this. The importance of this is reinforced by the NIHR, who include supporting personal development and learning opportunities among their goals for allied health professionals involved in research (NIHR, 2018a). The need for support in this area was also featured in discussion at the Physiotherapy Research Society Conference (2018). Allocation of adequate time to evaluate research and change practice was deemed important at that discussion.

Impact of involvement in the research and data collection process

The overwhelming response from participants was that involvement in the research process was beneficial. However, despite physiotherapy departments receiving full service support costs, few participants felt that their involvement in research was of positive benefit as a source of revenue. Others were unsure. This suggests a need for those physiotherapists collecting data to be made aware of the revenue they are generating and how that revenue is spent.

The majority of responses indicated positive benefits from their involvement in the research process. However, physiotherapists based in community services in particular reported a degree of inconvenience, which was largely based on time pressure. The study design included funded additional time for assessment of patients. It appears, however, that in practice, the physiotherapists in community services often did not have that extra time available. Research activity requires additional procedures and duties to be undertaken, and it may be that some organisations would 
benefit from reviewing their practice in this area. It should be emphasised, however, that no respondents reported that the inconvenience outweighed the benefit.

Limitations

This study addressed involvement in just one research project, and used self-reports of practice rather than observational findings from a third party; these are potential sources of bias. The sample represents just 21 of 115 physiotherapists and 3 of the 11 involved organisations, limiting the generalisability of findings. The questionnaire was designed to meet the needs of this study, but it was not validated before use. The interval of 4 years between data collection and physiotherapists completing our questionnaire creates potential for recall bias. Nevertheless, this study does provide a unique insight into the self-perceived impact of data collection from a range of physiotherapists.

\section{Conclusions}

The majority (71\%) of respondents stated they were aware of and understood the findings of the study, but only one third had gained their awareness through directly reading the published article. All respondents reported having made changes to clinical practice as a result of their involvement, but many reported some barriers to this; primarily lack of time and a perception that patients would not engage positively with a more psychosocial approach. Our findings strongly support the theory that clinicians benefit from involvement in the research process. Those involved in future research should consider other methods in addition to journal publication when disseminating their findings. If clinicians are to change practice as a result of their involvement in the research process, then additional time and resources may need to be allocated to them for this purpose.

\section{Acknowledgements}

We would like to thank Peter Swan, Senior Physiotherapist, Norfolk Community Health and Care NHS Trust, for his contribution towards the questionnaire development and various stages of data acquisition and analysis.

\section{References}

Bernhardsson S, Johansson K, Nilsen P, Öberg B, Larsson M. Determinants of guideline use in primary care physical therapy: a cross-sectional survey of attitudes, knowledge, and behaviour. Phys Ther. 2014;94(3):343-354. https://doi.org/10.2522/ptj.20130147

Boaz A, Hanney S, Jones T, Soper B. Does the engagement of clinicians and organisations in research improve healthcare performance: a three-stage review. BMJ Open. 2015;5(12):e009415. https://doi.org/10.1136/bmjopen-2015-009415

Chester R, Shepstone L, Lewis J, Jerosch-Herold C. Predicting response to physiotherapy treatment for musculoskeletal shoulder pain: protocol for a longitudinal cohort study. BMC Musculoskelet Disord. 2013;14(1):192. https://doi.org/10.1186/1471-2474-14-192

Chester R, Jerosch-Herold C, Lewis J, Shepstone L. Psychological factors are associated with the outcome of physiotherapy for people with shoulder pain: a multicentre longitudinal cohort study. $\mathrm{Br}$ J Sports Med. 2018;52(4):269-275. https://doi.org/10.1136/bjsports-2016-096084 
Clarke M, Loudon K. Effects on patients of their healthcare practitioner's or institution's participation in clinical trials: a systematic review. Trials. 2011;12(1):16.

https://doi.org/10.1186/1745-6215-12-16

Health Research Authority. UK policy framework for health and social care research. 2017a. https://www.hra.nhs.uk/planning-and-improving-research/policies-standards-legislation/uk-policyframework-health-social-care-research (accessed 11 February 2020)

Health Research Authority. Is my study research? 2017b. http://www.hradecisiontools.org.uk/research/ (accessed 11 February 2020)

Janssen J, Hale L, Mirfin-Veitch B, Harland T. Perceptions of physiotherapists towards research: a mixed methods study. Physiotherapy. 2016;102(2):210-216.

https://doi.org/10.1016/j.physio.2015.04.007

Kamwendo K. What do Swedish physiotherapists feel about research? A survey of perceptions, attitudes, intentions and engagement. Physiother Res Int. 2002;7(1):23-34.

https://doi.org/10.1002/pri.238

Metcalfe C, Lewin R, Wisher S et al. Barriers to implementing the evidence base in four NHS therapies: dieticians, occupational therapists, physiotherapists, speech and language therapists. Physiotherapy. 2001;87(8):433-441. https://doi.org/10.1016/S0031-9406(05)65462-4

National Institute of Health Research. NIHR CRN Allied Health Professionals Strategy 2018-2020. 2018a. https://www.nihr.ac.uk/documents/nihr-crn-allied-health-professionals-strategy-2018$\underline{2020 / 11530}$ (accessed 29 February 2020)

National Institute of Health Research. How to disseminate your research: getting your message heard: and used. 2018b. https://www.nihr.ac.uk/funding-and-support/documents/funding-forresearch-studies/manage-my-study/How-to-disseminate-your-research/dissemination-guidance.pdf (accessed 11 February 2020)

Physiotherapy Research Society. Conference. Panel discussion, Making research relevant in clinical practise: opportunities and challenges. Research and clinical practice: a two-way street, the 37th scientific meeting of the Physiotherapy Research Society. 19th April 2018.

https://www.physioresearch.org/index.php

Appendix 1

Shoulder Pain: Predicting Response to Physiotherapy Treatment

Thank You Physiotherapists

For collecting data for this study. 
You kindly collected data for this study between 2011 and 20153

We would now like to hear your views on the following:

- The impact of the results of the study on your practice

- The impact of your involvement in the research process (i.e. collecting data) on your practice

\begin{tabular}{|l|l|}
\hline Name (optional) & Grade \\
\hline Site & \\
& \\
\hline Email: (if you are happy to be contacted) \\
\hline Today's date
\end{tabular}

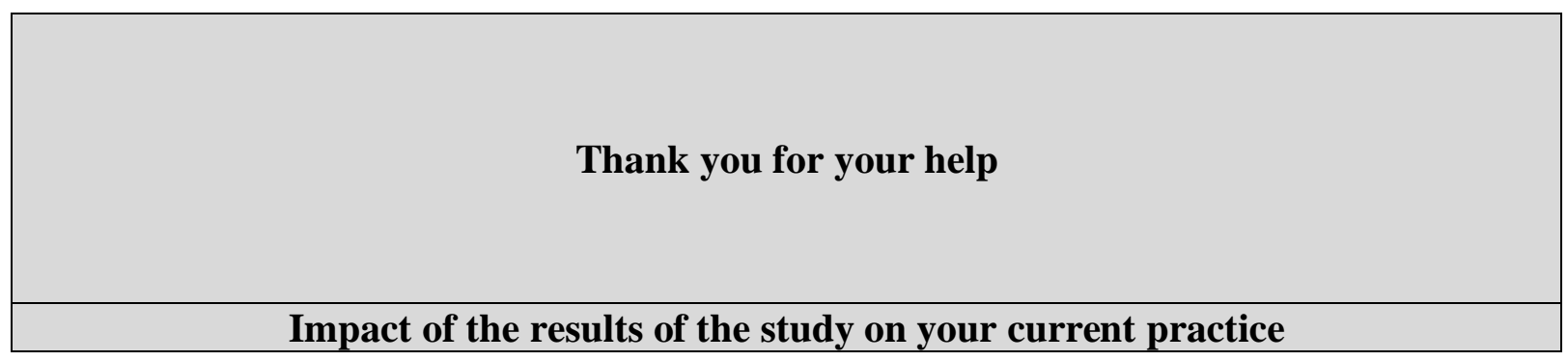

Are you aware of the results of the study?

\begin{tabular}{|c|c|c|c|}
\hline Yes & No & \\
\hline
\end{tabular}

If yes, how did you become aware? If no, why not? Please provide further details to help our understanding (For example, wasn't aware, not interested, too busy to prioritise reading)

Did you understand the results of the study?

\begin{tabular}{|c|c|c|c|}
\hline Yes & No & \\
\hline
\end{tabular}

Have the results changed your beliefs about factors contributing to the prognosis of people receiving physiotherapy for shoulder pain

\begin{tabular}{|l|l|l|l|l|l|}
\hline Yes & In Part & & No & \\
\hline
\end{tabular}

Please provide further details 
Has participation in, or knowledge of the study results indicated that it would be advantageous to change your subjective assessment of patients with musculoskeletal shoulder pain?

\begin{tabular}{|c|c|c|c|}
\hline Yes & No & \\
\hline
\end{tabular}

If yes, please explain in what way. If no, please explain why not.

Has participation in, or knowledge of the study results indicated that it would be advantageous to change your physical assessment of patients with musculoskeletal shoulder pain?

\begin{tabular}{|c|c|c|c|}
\hline Yes & No & \\
\hline
\end{tabular}

If yes, please explain in what way. If no, please explain why not.

Has participation in, or knowledge of the study results indicated that it would be advantageous to change your management of patients with musculoskeletal shoulder pain?

\begin{tabular}{|c|c|c|c|}
\hline Yes & No & \\
\hline
\end{tabular}

If yes, please explain in what way. If no, please explain why not.

Have the results of the study been incorporated into or changed any of your departmental, local or regional guidelines, pathways, or documentation.

\begin{tabular}{|c|c|c|c|}
\hline Yes & & No & \\
\hline
\end{tabular}

If yes, please explain. If no, please explain why not.

\section{Impact of the results of the study on your future practice}

What barriers/challenges have you come across when trying to integrate the results of the study into your assessment and management of patients with shoulder pain? 
What things have helped you integrate the results of the study into your assessment and management of patients with shoulder pain?

Have you identified any training needs for yourself or your department colleagues that have emerged as a result of the study?

\begin{tabular}{|c|c|c|c|}
\hline Yes & No & \\
\hline
\end{tabular}

If yes, what are these training needs?

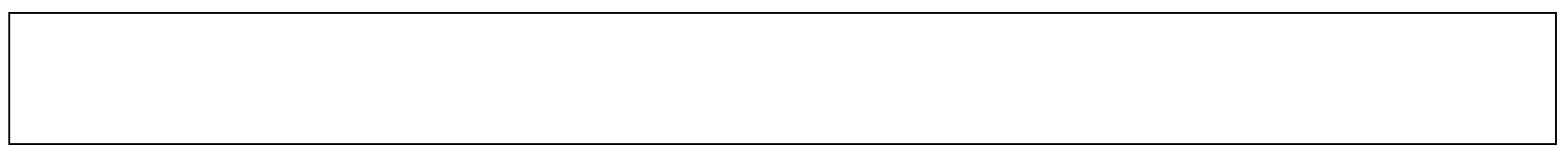

If yes, have these needs been met? (please tick one option)

\begin{tabular}{|l|l|l|l|l|l|}
\hline Fully & Partially & & Not at all & \\
\hline
\end{tabular}

Please add any additional comments below

Your INVOLVEMENT in collecting data for the shoulder study

Did being involved in this study change your understanding of the research process?

\begin{tabular}{|c|c|c|c|}
\hline Yes & No & \\
\hline
\end{tabular}

If yes, please explain how? If no, please explain why not?

How beneficial was your involvement in the research? 
Please tick one box for each statement where $0=$ of no benefit and $5=$ of maximum benefit

\begin{tabular}{|l|c|c|c|c|c|c|l|}
\hline $\begin{array}{l}\text { For your continuing professional } \\
\text { development }\end{array}$ & 0 & 1 & 2 & 3 & 4 & 5 & Unsure \\
\hline $\begin{array}{l}\text { As a source of revenue for the } \\
\text { physiotherapy department }\end{array}$ & 0 & 1 & 2 & 3 & 4 & 5 & Unsure \\
\hline $\begin{array}{l}\text { As kudos for your physiotherapy } \\
\text { department }\end{array}$ & 0 & 1 & 2 & 3 & 4 & 5 & Unsure \\
\hline For "patient/person centred care" & 0 & 1 & 2 & 3 & 4 & 5 & Unsure \\
\hline For the physiotherapy profession & 0 & 1 & 2 & 3 & 4 & 5 & Unsure \\
\hline
\end{tabular}

Was your involvement in the research an inconvenience?

\begin{tabular}{|c|c|c|c|}
\hline $\begin{array}{c}\text { Yes, it was more of an } \\
\text { inconvenience than of } \\
\text { any benefit }\end{array}$ & $\begin{array}{c}\text { Yes, rather } \\
\text { inconvenient, but } \\
\text { worth it }\end{array}$ & $\begin{array}{c}\text { A little inconvenient } \\
\text { but not noticeably }\end{array}$ & $\begin{array}{c}\text { No inconvenience at } \\
\text { all }\end{array}$ \\
\hline
\end{tabular}

Did being involved in this study change your view of the value of research?

$$
\begin{array}{l|l|l}
\text { Yes } & \text { No }
\end{array}
$$

If yes, please explain how. If no, please explain why not. 